\title{
Review of: "Inoculation of Herbaspirillum Seropedicae Increases Biomass in Maize Roots in the Early Stages of Plant Development"
}

\author{
Everlon Rigobelo ${ }^{1}$ \\ 1 Universidade Estadual Paulista
}

Potential competing interests: The author(s) declared that no potential competing interests exist.

The present study "Inoculation of Herbaspirillum Seropedicae Increases Biomass in Maize Roots in the Early Stages of Plant Development" evaluated the Herbaspirillum seropedica inoculation on maize plants. This study has shown some differences in the plant growth related to treatments carried out.

The success of plant growth-promoting rhizobacteria such as Herbaspirillum seropedica depends on the plant-microbe interaction.

Plant microbe-interaction is affected by soil type, bacteria strain, environment, edaphic conditions, mainly plant genotype.

The present study presented some increases promoted by $\mathrm{H}$. seropedica inoculation on maize.

The results do not bring novelties. I think the strength of this study is to show the interaction of $\mathrm{H}$. seropedica with the maize genotype DKB390.

Material and Methods section

Could the authors explain better the treatments carried out?

These two experiments were carried out with the same treatments? What was the effect of seasons if the environmental conditions were controlled?

The design of these experiments is confusing.

"The first factor consisted of bacterial inoculation (or control non-inoculated high $\mathrm{N}$ and low $\mathrm{N}$ ).

High $\mathrm{N}$ and low $\mathrm{N}$ did receive bacterial inoculation?

Could the authors explain better figure 4? I did not understand how these curves were made. What was the difference between them?

Why was the curve in figure 4A made if the control did not receive the bacterial inoculation?

The results were repeated in the discussion section and not discussed.

The authors should explain the differences found between these two experiments. How could the season have affected the bacterial performance? 
